\title{
Polygenic control of a mating signal in Drosophila
}

\author{
ADRIAN R. G. PUGH \& MICHAEL G. RITCHIE* \\ Biological and Medical Sciences, Bute Medical Building, University of St Andrews, St Andrews, Fife KY16 $97 S$, U.K.
}

\begin{abstract}
Recent findings show that traits which influence speciation in the melanogaster subgroup of Drosophila can be determined by relatively few loci and/ or be sex-linked. Using backcrosses between $D$. simulans and $D$. mauritiana, we show that an acoustic mating signal which plays an important role in courtship (the interpulse interval of the 'lovesong') has a polygenic determination. There is no evidence of single genes of large effect, a disproportionate contribution of the sex chromosome or epistasis. The probability of finding single genes with a large effect on sexual isolation may vary with the mode of signalling involved.
\end{abstract}

Keywords: courtship song, Drosophila, interpulse interval, speciation.

\section{Introduction}

Speciation is caused by the evolution of reproductive isolation between diverging taxa (Mayr, 1963; Dobzhansky, 1951), usually as a side-effect of divergence (Butlin \& Ritchie, 1993; Paterson, 1993). Understanding the details of this process requires a knowledge of the traits that determine reproductive isolation, and the genetic changes necessary to cause differences between species. Substantial progress has been made in understanding the chromosomal distribution and evolution of genes that cause postmating isolation (hybrid infertility or inviability). Haldane's Rule (Haldane, 1922), which states that the heterogametic sex (e.g. the XY males of mammals and Drosophila) is the first to show dysfunction in interspecific crosses, might result from a disproportionate role of the sex chromosome in speciation, although most theories also require epistatic interaction with autosomal genes (Coyne \& Orr, 1989; Coyne, 1992a; Orr, 1993). Premating signals may be a more important cause of reproductive isolation in many animals (Butlin \& Ritchie, 1993). Common patterns in the divergence of genes influencing sexual isolation have yet to be described, probably because these are more difficult to study. Some authors have stated that the sex chromosomes may also play a disproportionate role in behavioural isolation (Ewing, 1969; Charlesworth et al., 1987; Reinhold, 1994), and others have said that single genes may also often be involved (Henry, 1994). There is empirical evidence both for and against

${ }^{*}$ Correspondence. these positions, but as yet no clear picture has emerged. Here we report an experiment to determine the distribution of genes influencing a speciesspecific mating signal in Drosophila simulans and $D$. mauritiana.

There are two types of signal which have a large influence on courtship in species of the melanogaster group of Drosophila: pheromonal blend differences and acoustic signals produced by wing vibration. Males will not court females with an inappropriate pheromone blend (Jallon, 1987; Cobb \& Jallon, 1990), and male pheromones can also influence female preference (at least in D. melanogaster, Scott, 1994). A major difference in female pheromone blend between $D$. simulans and $D$. sechellia (from mainly 7,11-heptacosadiene in D. sechellia to mainly 7 -tricosene in $D$. simulans) is largely caused by a gene or genes on one autosome (Coyne et al., 1994). Songs produced by wing vibration are also an important component of courtship. Females will mate only very reluctantly with males silenced by wing removal but replaying synthetic song can at least partially restore male mating success. Such experiments have shown that an important component of this signal is pulse song, in particular, mean interpulse interval (IPI) and a patterned cycle in IPI (Bennet-Clark \& Ewing, 1969; Kyriacou \& Hall, 1982, 1986; van den Berg, 1988; Greenacre et al., 1993). The length of the song IPI cycle of $D$. melanogaster and $D$. simulans is determined by the sex-linked period gene (Wheeler et al., 1991). The genetics of mean IPI is less well understood. Within D. melanogaster, mean IPI has a low variability and heritability (Ritchie \& Kyriacou, 1994; Ritchie et al., 
1994) yet it differs greatly between the species of the melanogaster group (Cowling \& Burnet, 1981).

The existence of fertile $F_{1}$ females in crosses between certain species of Drosophila, most notably those of the simulans clade of the melanogaster group, has allowed some analysis of the number of genes influencing sexual isolation by following the cosegregation of traits with morphological marker genes (Coyne, 1992b; Tomaru \& Oguma, 1994a). Here we find that genes determining the difference in mean IPI between $D$. simulans and $D$. mauritiana are distributed evenly throughout the genome, with genes on each major chromosome arm contributing approximately equally to the difference between species. We suggest that some signalling modes may be more likely to show quantitative polygenic variation than others.

\section{Materials and methods}

\section{Stocks}

We have used a stock of $D$. simulans which contains recessive morphological marker genes on the $\mathrm{X}$ chromosome and each arm of the autosomes in a backcrossing experiment with $D$. mauritiana. The marker genes of $D$. simulans used (all recessive) were $f^{2}$ (forked, twisted short bristles) on the $\mathrm{X}$ chromosome (Map reference 1-56.7), nt (net, wing venation) left arm (2-0.0), and pm (plum, eye colour) on the right arm (2-104.5) of the second chromosome, $e$ (ebony, body colour) on the right arm (3-70.7) and st (scarlet, eye colour) on the left arm (3-44) of the third chromosome. The fourth 'dot' chromosome was unmarked but represents less than 0.5 per cent of the genome of these species of Drosophila. As well as for their chromosomal location, these markers were chosen as they did not involve large changes in wing morphology or muscle physiology. $F_{1}$ stocks were established by mass mating ten virgin $D$. mauritiana males with ten virgin $D$. simulans homozygous multiple mutant females. Backcross stocks were set up using ten virgin $F_{1}$ females and ten virgin $D$. simulans homozygous multiple mutant males per cross. Standard $D$. melanogaster techniques (sugar/yeast agar medium, $25^{\circ} \mathrm{C}, \quad 12: 12 \mathrm{~L}: \mathrm{D}, \mathrm{CO}_{2}$ anaesthesia) were used throughout. The mutant strains of $D$. simulans were obtained from the Drosophila spp. stock centre, Bowling Green, Ohio. The Leticia (Columbia) and Ruratonga (Cook Islands) strains of $D$. simulans were obtained from the laboratory of Dr C. P. Kyriacou, and the Seychelles strain of $D$. simulans and $D$. mauritiana were from that of Prof. J. David.
These strains have all been in laboratory culture for several years.

\section{Song analysis}

Songs of 2-6 day-old males were recorded using a custom-built 'insectavox' microphone (Gorczyca \& Hall, 1987) and a Marantz cassette tape recorder. Females used were silenced by wing removal, because noise from the females can interfere with the semi-automatic measurement of IPI. Recordings were made for $5 \mathrm{~min}$ from the first burst of pulse song. Females used were of the same stock as the male, except that the (morphologically wild-type) parental $D$. mauritiana strain females were used to obtain backcross male courtship. Temperature was recorded as the average of that at the beginning and end of each recording. Song was digitized using a Cambridge Electronic Design $1401 \mathrm{~A} / \mathrm{D}$ converter (at $2 \mathrm{kHz}$ after bandpass filtering at around $200 \mathrm{~Hz}$ to $1 \mathrm{kHz}$ ). Individual pulses of song were detected using an automatic procedure, with subsequent manual monitoring of data points and song pattern by the experimenter. All analysis used customwritten scripts in the 'SPIKE2' language (copyright C.E.D.). These procedures have been checked for accuracy (Ritchie \& Kyriacou, 1994). Variation in IPI has been shown to cycle in $D$. simulans with an approximately $1.5 \mathrm{~min}$ periodicity. The analysis of 5 min meant all parts of the cycle were sampled. Histograms of the IPIs detected in each recording were examined (Fig. 1). The IPI value of each male entered into the analysis was the modal IPI from the recording, because of the skew towards longer values (in the case of ties, the average of the most frequent IPIs was used). The skewing was more pronounced in $D$. mauritiana. Longer IPIs were found at the beginning and end of bursts of song and it has been suggested that females respond to the modal, not mean, IPI (Cowling \& Burnet, 1981). Modal and mean IPI are highly correlated in $D$. simulans ( $r=0.601, n=69, P<0.001)$ and the modal IPIs per recording were themselves normally distributed.

\section{Results and discussion}

Table 1 compares the song of the homozygous multiple mutant stock with three arbitrarily chosen laboratory adapted wild-type $D$. simulans stocks. There was significant variation between stocks $\left(F_{3,62}=4.56, P=0.006\right)$ but the mutant stock did not differ from the pooled wild-type stocks $\left(t_{59}=1.16\right.$, NS), suggesting that the mutations had no direct 

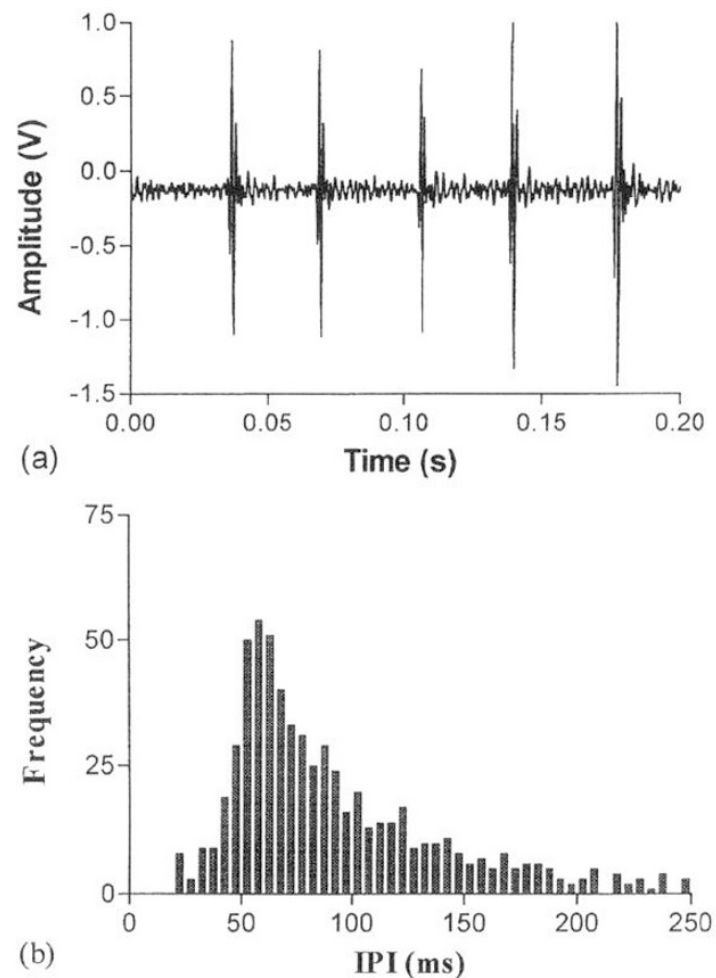

Fig. 1 (a) Song of Drosophila mauritiana showing pulses. (b) Representative histogram of IPIs from a 5-min recording of a single courtship.

effect on song phenotype. Eighteen $F_{1}$ males from the $D$. simulans female $\times D$. mauritiana male cross were recorded and had an IPI which did not differ significantly from the midparental value $\left(t_{19}=1.11\right.$, NS). The reciprocal cross produced few males. None of these sang (Lemeunier et al., 1986). Homozygous multiple marked males were crossed to $(D$. simulans female $\times D$. mauritiana male) $\mathrm{F}_{1}$ females; 177 backcross males were recorded, covering 26 of the 32 possible genotypes (Fig. 2). One-way anova indicated no significant differences between genotype classes grouped according to the number of marker genes they contained, i.e. IPIs of all genotypes containing one marker gene did not differ significantly regardless of the location of the gene $\left(F_{3,37}=0.88, \mathrm{NS}\right)$, and the same was true when grouping genotypes containing two $\left(F_{6,37}=1.02\right.$, NS), three $\left(F_{4,24}=1.29, \mathrm{NS}\right)$, or four markers $\left(F_{1,6}=1.58\right.$, NS). This suggests an additive architecture, lacking epistasis. To examine further the polygenic additive nature of these effects, we tested each of these genotypic groups against an 'expected' IPI, calculated assuming each $D$. simulans marker gene identifies a proportion of the genome contributing one-fifth of the difference in IPI between the species (Fig. 3). None differed significantly from this value.
Table 1 Mean IPI (ms) of mutant and wild-type stocks of Drosophila simulans

\begin{tabular}{lcccc}
\hline Stock & $N$ & IPI & SE & Range \\
\hline Wild-type & & & & \\
$\quad$ Seychelles & 15 & 52.38 & 2.50 & $37.69-73.45$ \\
$\quad$ Leticia & 16 & 54.53 & 1.46 & $46.07-69.46$ \\
$\quad$ Ruratonga & 14 & 46.50 & 1.14 & $37.69-51.71$ \\
Pooled wild-type & 45 & 51.31 & 1.14 & $37.69-73.45$ \\
Mutant & 21 & 49.55 & 1.02 & $41.85-58.02$ \\
\hline
\end{tabular}

Each mean is the mean of the modal IPI per male. There was no correlation of modal IPI per recording with temperature (probably reflecting the low range of recording temperature: $22.5-27.5^{\circ} \mathrm{C}$, mean $=25.56^{\circ} \mathrm{C}$, $\mathrm{SD}=1.1^{\circ} \mathrm{C}$ ) and therefore no correction was made. The mean IPI of $D$. mauritiana is $35.7 \mathrm{~ms}(\mathrm{SE}=1.04, n=15)$.

These results suggest that the difference in mean IPI between the courtship songs of these species is determined by additive genes distributed evenly throughout the genome. There is no evidence of a greater than proportional contribution of the X-linked marker or of any epistasis between different genomic regions. Similar results have been found in a study of mean IPI in crosses between the $D$. auraria and $D$. biauraria spp. of the $D$. auraria complex (Tomaru \& Oguma, 1994a; using three markers), in which IPI is also species-specific (Tomaru \& Oguma, 1994b) and in studies of assortative mating between recombinant genotypes of $D$. sechellia and D. simulans (Coyne, 1992b). These behaviours are known to comprise a major component of the mate recognition systems of these species (e.g. Tomaru et al., 1995), so it does not seem to be the case that polygenic determination results because these are not subject to selection.

In contrast, studies of pheromone blend difference between $D$. simulans and $D$. sechellia have implied a possible role for single genes, as the blend difference cosegregates with a marker of the third chromosome and, intriguingly, female preference for the Tai-Y \& CS male pheromonal phenotypes of $D$. melanogaster is influenced by a gene or genes on the same chromosome (Coyne et al., 1994; Scott, 1994). Single genes of large effect are also commonly seen in pheromonal studies of moths (Löfstedt et al., 1989; Löfstedt, 1993). It may therefore be the case that the mode of signalling used by a species influences the likelihood of single genes exerting a large effect on the phenotype. Song patterns are primarily neuronally encoded and involve complex synchronization of a range of body structures, whereas a single protein component may be more likely to 


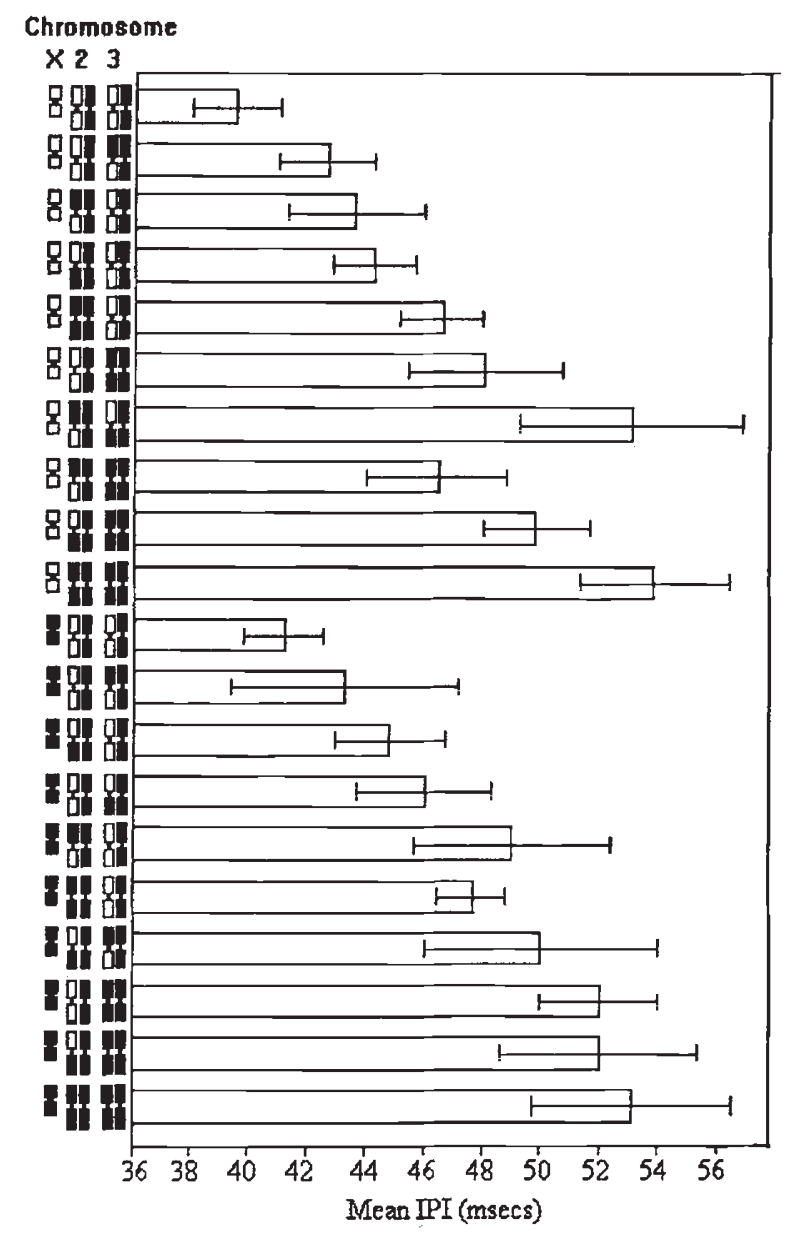

Fig. 2 IPI of backcross genotypes. Shading of chromosomes indicates the species of origin of the marker gene of each genotype (empty = Drosophila mauritiana; filled $=D$. simulans; recombination within a chromosome arm in the $F_{1}$ is ignored). Mean sample size per genotype is 6.185 (range 1-20; error bars are $\pm \mathrm{SE}$; six genotypes for which $n=1$ are not included in the figure). Note that the genotypes are first arranged according to the origin of the X chromosome, but no step is apparent in the IPI data. This would be expected if sex-linked genes made a major contribution to the differences between species.

have a large effect on pheromone blend component, particularly if acting late in the developmental pathway. It may also be easier to envisage a single gene influencing female preference for a protein detection system as opposed to a neural signal processing system.

Nevertheless, the period gene provides a striking example of a single gene of large effect on a complex song trait (Wheeler et al., 1991), and other single genes of large effect have been implicated in acoustic (Henry, 1994), visual (Majerus et al., 1986) and vibrational (Stratton \& Uetz, 1986) modes of sexual signalling behaviour (although the evidence is

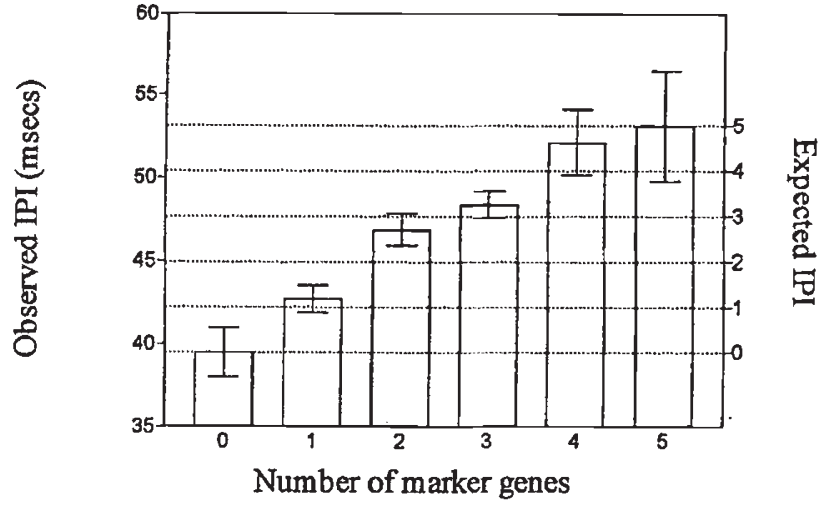

Fig. 3 Comparison of observed IPI (columns, \pm SE) with that expected (dotted lines) if each of the five marker genes identifies one-fifth of the difference between the species and there is no epistasis, i.e. the expected value is simply the number of Drosophila simulans genes times 0.2 of the difference between the $\mathrm{F}_{1}$ and the parental $D$. simulans IPIs.

less clear in these cases than in that of period and moth pheromones). Further studies are required to clarify any general pattern, and the application of quantitative trait loci techniques to behavioural traits will be extremely important. These techniques are already showing that variation in quantitative traits of ecological importance can result from segregation at single loci (Bradshaw et al., 1995; MitchellOlds, 1995). But the nature of so-called 'speciation genes' (i.e. genes which influence speciation, although very few could have been selected for that purpose) remains elusive. Many forms of sexual isolation may be polygenically determined and therefore may only diverge relatively slowly, probably in allopatry, as envisaged by important contributors to the neo-Darwinian synthesis (Orr \& Coyne, 1992).

\section{Acknowledgements}

We thank Prof. J. David and Dr C. P. Kyriacou for kindly supplying some of the stocks used. This research was funded by the SERC/BBSRC (studentship 93309713 to A.P.) and NERC (Fellowship GT5/92/TLS/16 to M.G.R.). The manuscript was improved following helpful comments from referees.

\section{References}

BENNET-CLARK, H. C. AND EWING, A. w. 1969. Pulse interval as a critical parameter in the courtship song of Drosophila melanogaster. Anim. Behav., 17, 755-759.

BRADSHAW, H. D., WILBERT, S. M., OTTO, K. G. AND SCHEMSKE, D. W. 1995. Genetic-mapping of floral traits 
associated with reproductive isolation in Monkeyflowers (Mimulus) Nature, 376, 762-765.

BUTLIN, R. K. AND RITCHIE, M. G. 1993. Behaviour and speciation. In: Slater, P. J. B. and Halliday, T. R. (eds) Behaviour and Evolution, pp. 43-79. Cambridge University Press, Cambridge.

CHARlesworTh, B., COYNE, J. A. AND BARTON, N. H. 1987. The relative rates of evolution of sex chromosomes and autosomes. Am. Nat., 130, 113-146.

COBB, M. AND JALlon, J.-M. 1990. Pheromones, mate recognition and courtship stimulation in the Drosophila melanogaster species subgroup. Anim. Behav., 39, 1058-1067.

COWLING, D. E. AND BURNET, B. 1981. Courtship song and genetic control of their acoustic characteristics in sibling species of the Drosophila melanogaster subgroup. Anim. Behav., 29, 924-935.

COYNE, J. A. 1992a. Genetics and speciation. Nature, 355, $511-515$

COYNe, J. A. 1992b. Genetics of sexual isolation in females of the Drosophila simulans species complex. Genet. Res., 60, 25-31.

COYNE, J. A., CRITTENDEN, A. P. AND MAH, K. 1994. Genetics of a pheromonal difference contributing to reproductive isolation in Drosophila. Science, 265, 1461-1464.

COYNE, J. A. AND ORR, H. A. 1989. Two rules of speciation. In: Otte, D. and Endler, J. A. (eds) Speciation and its Consequences, pp. 180-207. Sinauer, Sunderland, MA.

DOBZHANSKY, T. 1951. Genetics and the Origin of Species, 3rd edn. Columbia University Press, New York.

EWING, A. w. 1969. The genetic basis of sound production in Drosophila pseudoobscura and D. persimilis. Anim. Behav., 17, 555-560.

GORCZYCA, M. AND HALL, J. C. 1987. The Insectavox, an integrated device for recording and amplifying courtship songs of Drosophila. Drosoph. Inf. Serv., 66, $157-160$.

GREENACRE, M., RITCHIE, M. G., BYRNE, B, C. AND KYRIACOU, C. P. 1993. Female song preference and the period gene of Drosophila melanogaster. Behav. Genet., 23, 85-90.

HALDANE, J. B. S. 1922. Sex-ratio and unisexual sterility in hybrid animals. J. Genet., 12, 101-109.

HENRY, C. S. 1994. Singing and cryptic speciation in insects. Trends Ecol. Evol., 9, 388-392.

JALLON, J.-M. 1987. Variations in cuticular hydrocarbons among the eight species of the Drosophila melanogaster subgroup. Evolution, 41, 294-302.

KYRIACOU, C. P. AND HALL, J. C. 1982. The function of courtship song rhythms in Drosophila. Anim. Behav., 30, 794-801.

KYRIACOU, C. P. AND HALL, J. C. 1986. Interspecific genetic control of courtship song production and reception in Drosophila. Science, 232, 494-497.

LEMEUN1ER, F., DAV1D, J. R., TSACAS, L. AND ASHBURNER, M. 1986. The melanogaster species group. In: Ashburner, M., Carson, H. L. and Thompson, J. J. N. (eds) The Genetics and Biology of Drosophila, vol. 3e, pp. 147-256. Academic Press, London.
LÖFSTEDT, C. 1993. Moth pheromone genetics and evolution. Phil. Trans. R. Soc. B, 340, 167-177.

LÖFSTEDT, C., HANSSON, B. S., ROELOFS, W. AND BENGTSSON, B. O. 1989. No linkage between genes controlling female pheromone production and male pheromone response in the European corn borer, Ostrinia nubilalis Hübner (Lepidoptera; Pyralidae). Genetics, 123, 553-556.

MAJERUS, M. E. N., O'DONALD, P., KEARNS, P. W. E. AND IRELAND, H. 1986. Genetics and the evolution of female choice. Nature, 321, 164-167.

MAYR, E. 1963. Animal Species and Evolution. Harvard University Press, Cambridge, MA.

MITCHELL-OLDS, T. 1995. The molecular basis of quantitative genetic variation in natural populations. Trends Ecol. Evol., 10, 324-328.

ORR, H. A. 1993. Haldane's rule has multiple genetic causes. Nature, 361, 532-533.

ORR, H. A. AND COYNE, J. A. 1992. The genetics of adaptation: a reassessment. Am. Nat., 140, 725-742.

PATERSON, H. E. H. 1993. Evolution and the Recognition Concept of Species. Johns Hopkins University Press, Baltimore.

REINHOLD, K. 1994. Inheritance of body and testis size in the bushcricket Poecilimon veluchianus Ramme (Orthoptera; Tettigoniidae) examined by means of subspecies hybrids. Biol. J. Linn. Soc., 52, 305-316.

RITCHIE, M. G. AND KYR1ACOU, C. P. 1994. The genetic variability of courtship song in a population of Drosophila melanogaster. Anim. Behav., 45, 425-434.

RITCHIE, M. G., YATE, V. H. AND KYRIACOU, C. P. 1994. Genetic variability of the interpulse interval of courtship song among some European populations of Drosophila melanogaster. Heredity, 72, 459-464.

scoTt, D. 1994. Genetic variation for female mate discrimination in Drosophila melanogaster. Evolution, $\mathbf{4 8 ,}$ 112-121.

STRATtON, G. E. AND UETZ, G. w. 1986. The inheritence of courtship behavior and its role as a reproductive isolating mechanism in two species of Schizocosa wolf spiders (Araneae: Lycosidae). Evolution, 40, 129-141.

TOMARU, M. AND OGUMA, Y. 1994a. Genetic basis and evolution of species-specific courtship song in the Drosophila auraria complex. Genet. Res., 63, 11-17.

TOMARU, M. AND OGUMA, Y. 1994b. Differences in courtship song in the species of the Drosophila auraria complex. Anim. Behav., 47, 133-140.

TOMARU, M., MATSUbayashi, H. AND Oguma, Y. 1995. Heterospecific inter-pulse intervals of coursthip song elicit female rejection in Drosophila biauraria. Anim. Behav., 50, 905-914.

VAN DEN BERG, M. J. 1988. Assortative Mating in Drosophila melanogaster and Among Three Species of the melanogaster Subgroup. Ph.D. Thesis, University of Groningen, The Netherlands.

WHEELER, D. A., KYRIACOU, C. P., GREENACRE, M. L., YU, Q., RUTILA, J. E., ROSBASH, M. AND HALl, J. C. 1991. Molecular transfer of a species-specific behavior from Drosophila simulans to Drosophila melanogaster. Science, 251, 1082-1085. 